\title{
SALIVARY GLANDS
}

\section{Use of the SMAS flap for reconstruction of the parotid lodge}

\author{
L'utilizzo del lembo di SMAS per ricostruzioni della loggia parotidea

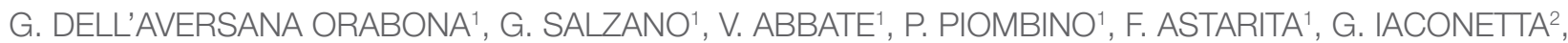 \\ L. CALIFANO ${ }^{1}$ \\ ${ }^{1}$ Maxillofacial Surgery Unit, Department of Neuroscience, Reproductive and Odontostomatological Science, \\ Federico II University; ${ }^{2}$ Neurosurgery Department, University of Salerno, Salerno, Italy
}

\section{SUMMARY}

The purpose of our study was to evaluate the benefits of the SMAS flap in patients with benign tumours of the parotid gland treated by superficial parotidectomy. We carried out a retrospective chart review on 123 patients suffering from benign tumours of the parotid gland admitted to our Institution between March 1997 and March 2010. A superficial parotidectomy was performed in all the cases reported. Our sample was divided in two groups basing SMAS flap reconstruction done (Group 2) or not (Group 1) after superficial parotidectomy. Reconstruction using SMAS flap was accomplished in 64 patients. Chi-square test was used to assess statistical difference between the two groups. The level of statistical significance was $\mathrm{P}<0.05$. No significant differences concerning hematoma, wound infection and facial paralysis were observed between the first and second group (3.38 vs $1.56 \%$ [P $>0.05], 8.47 \%$ vs $4.68 \%$ [P $>0.05], 5.08 \%$ vs $0.00 \%$ $[\mathrm{P}>0.05])$. Transient facial nerve weakness, fistula, dip skin and Frey's syndrome were significantly more frequent without SMAS flap reconstruction $(10.16 \%$ vs $3.125 \%$ [P < 0.05], $13.55 \%$ vs $3.125 \%$ [P < 0.05], $13.55 \%$ vs $3.125 \%$ [P < 0.05], 20.33\% vs $0 \%$ [P < 0.05$]$ respectively). The use of the SMAS flap is able to reduce the cosmetic and functional complications that occur after the removal of a benign tumour of the parotid through the superficial parotidectomy technique, above all, it reduces the occurrence of Frey's syndrome.

KEY WORDS: SMAS flap • Parotidectomy • Frey syndrome $\bullet$ Facial nerve palsy

\section{RIASSUNTO}

Lo scopo dello studio è stato quello di valutare i benefici della ricostruzione con lembo di SMAS nei pazienti affetti da neoplasie benigne della parotide e sottoposti a parotidectomia superficiale. Abbiamo condotto uno studio retrospettivo su 123 pazienti affetti da neoplasie benigne della ghiandola parotide ricoverati presso il Nostro istituto tra il Marzo 1997 e Marzo 2010. Tutti i pazienti arruolati sono stati sottoposti a parotidectomia superficiale. Il Nostro campione è stato diviso in due gruppi in base alla esecuzione (Gruppo 2) o no (Gruppo 1) di ricostruzione con lembo di SMAS dopo la parotidectomia superficiale. La ricostruzione con lembo di SMAS è stata eseguita in 64 pazienti. Un test chi quadro è stato utilizzato per valutare le differenze statistiche tra i due gruppi. Il livello di significatività statistica scelto è stato di $p<0,05$. Non è stata rilevata differenza statisticamente significativa tra i 2 gruppi per quanto riguarda l' insorgenza di ematoma, infezione della ferita e paralisi del faciale (3,38 vs 1,56\% [P>0,05], 8,47\% vs 4,68\% [P>0,05, 5,08\% vs 0,00\%). La paralisi transitoria del facciale, la fistola, la depressione della cute e la sindrome di Frey sono significativamente più frequenti nei pazienti non ricostruiti con lembo di SMAS $(10,16 \%$ vs 3,125\% [P < 0,05], 13,55\% vs 3,125\% $[P<0,05], 13,55 \%$ vs 3,125\% [P<0,05], 20,33\% vs 0\% [P<0,05], rispettivamente). Il lembo di SMAS è capace di ridurre le complicanze funzionali ed estetiche che si verificano dopo la rimozione di un tumore benigno della parotide mediante parotidectomia superficiale, tra queste, riduce il verificarsi della sindrome di Frey.

PAROLE CHIAVE: Lembo di SMAS • Parotidectomia $\bullet$ Sindrome di Frey $\bullet$ Paralisi del nervo facciale

Acta Otorhinolaryngol Ital 2015;35:406-411

\section{Introduction}

Benign tumours of the parotid gland account for $70 \%$ of all salivary glands tumours ${ }^{1}$. The literature shows that usually about 8 out of 10 salivary gland tumours are benign. The treatment of choice in the case of benign parotid tumours with a diameter greater than $3 \mathrm{~cm}$ located in the superficial portion of the parotid gland is superficial parotidectomy ${ }^{2}$. This technique is also used in the case of tumour recurrence because it allows maintaining safety margins. Superficial parotidectomy is not free from complications; we report depression of the skin, salivary fistula, transient or persistent facial nerve paralysis, cap- 
sular rupture and Frey's syndrome ${ }^{3-6}$. Frey syndrome or auriculotemporal nerve syndrome was described for the first time by Lucy Frey in $1923^{7}$ and is characterised by the appearance of redness, pain, sweating and heat in the parotid region following by gustatory stimulus. It is caused by an aberrant regeneration of injured postganglionic secretomotory parasympathetic nerve fibres of the auriculotemporal nerve after parotidectomy ${ }^{89}$. Thanks to the face-lift incision introduced by Appiani and Delfino ${ }^{10}$ (1984) and the use of superficial muscoloaponeurotic system (SMAS) flap introduced by Rapaport and Allison in $1985^{11}$, there has been reduction of cosmetic and functional post-parotidectomy complications ${ }^{12}$. The SMAS flap is a biological barrier capable of filling the cavity that is formed after removal of the tumour. The withdrawal of the SMAS flap is contextual to parotidectomy and increases surgical times very little (about $15 \mathrm{~min})^{13}$. The aim of our study was to compare postoperative outcomes after superficial parotidectomy in patients who receive or not parotid lodge reconstruction with SMAS flap.

\section{Materials and methods}

We carried out a retrospective chart review of 123 patients suffering from benign tumours of the parotid gland admitted to our Institution between March 1997 and March 2010. Patients had to meet the following inclusion criteria: - diagnosis of benign parotid tumour (pleomorphic adenoma or cystadenolymphoma);

- indication for superficial parotidectomy;

- possible reconstruction with SMAS flap;

- modified face-lift incision.

Our cohort was divided in two groups:

- Group 1 = 59 patients treated with superficial parotidectomy. In these cases, no flap reconstruction of the parotid lodge was used;

- Group $2=64$ patients treated with superficial parotidectomy and reconstructed with SMAS flap.

The decision of whether to use a SMAS flap or not was made individually by the surgeon who operated on each patient.

All patients underwent pre-operative diagnosis of parotid disease through colour Doppler ultrasonography, magnetic resonance or contrast-enhanced computed tomography, and fine needle aspiration cytology (FNAC) ${ }^{14}$.

Patients had a minimum follow-up of 48 months and maximum of 120 months; mean of 84 months. All patients were screened for scarring and facial nerve functionality (Fig. 1). We also verified the presence of Frey's syndrome using the minor starch iodine test ${ }^{15}$. One month after surgery each patient was administered a questionnaire to measure the degree of postoperative satisfaction on a visual analogue scale from 1 to 10 . Values ranges from 1 to 3 showed a poor result, from 4 to 7 a good result and from 8 to 10 an excellent result.

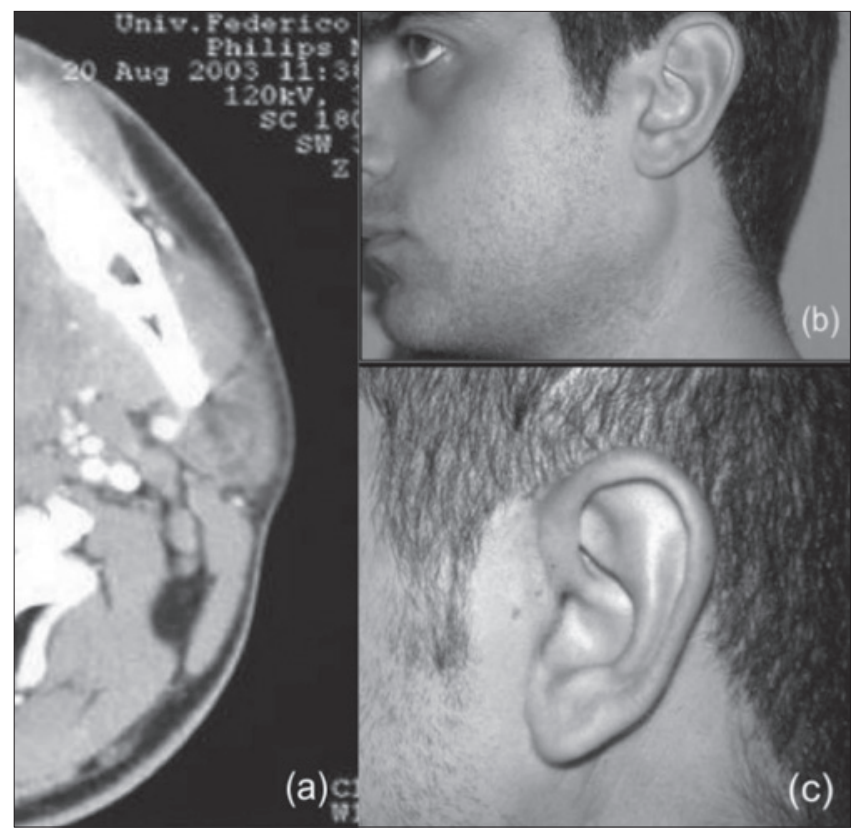

Fig. 1. (a) Pre-operative axial CT scan showing a left parotid lesion; (b) pre-operative patient appearance showing swelling on the left parotid region; (c) scar at 6 months follow-up.

Statistical calculations were performed with the Statistical Package for Social Sciences (version 17.0; SPSS, Chicago, IL). The difference between groups regarding evaluated recurrence rate and complications was measured with a $\chi^{2}$ test. The level of statistical significance was $P<0.05$.

\section{SMAS flap}

The SMAS is a layer of muscle fibre and connective tissue located just under the skin and over the parotid fascia. Its function is to transmit, distribute and amplify the activity of all facial muscles ${ }^{13}$.

The SMAS continues anteriorly in the mid-cheek area with the zygomatic muscles; above with the temporoparietal fascia and below with the platysma muscle.

On the upper side, the preparation of the SMAS flap consists of a horizontal incision $1 \mathrm{~cm}$ below the zygomatic arch reaching the malar eminence, and a vertical incision in the preauricular region along the posterior portion of the platysma muscle that continues until finding a point placed 5-6 cm from the bottom of the mandibula ${ }^{116}$.

The dissection is done very carefully to avoid any damage to the branches of the facial nerve. Once the flap is established it is possible to proceed with superficial parotidectomy. After the procedure is completed, reconstruction was accomplished by suturing the SMAS on the zygomatic periosteum and parotid-masseteric fascia ${ }^{13}$ (Fig. 2).

\section{Results}

A total of 123 patients were enrolled, 56 women and 67 men (average age 51 years); 98 adenomas and 25 cystad- 
enolynphomas were diagnosed on the histopathological report. Superficial parotidectomy was performed in all the cases reported. We performed reconstruction with SMAS flap in 64 patients. In Group 1, we found 6 cases of transient paralysis of the facial nerve, 1 case of facial paralysis, 12 Frey's syndrome, 8 skin depressions, 8 salivary fistulas, 2 wound infections and 5 haematoma. In Group 2, there were no cases of Frey's syndrome. We encountered 2 cases of transient paralysis of the facial nerve, 2 cases of salivary fistula, 2 cases of skin depression, 1 wound infection, no facial paralysis and 3 haematomas. We also evaluated the satisfaction in patients with and without SMAS flaps reconstruction; 53 of 64 patients operated with SMAS flap (Group 2) achieved an excellent result, and 11 patients had a good result. In patients without SMAS flap reconstruction (Group 1), the degree of satisfaction was much more variable; 15 patients reported a poor result, 18 patients an excellent result and 26 patients a good result. Table I shows outcome results of $\chi^{2}$ test comparing the first and the second group: except for wound infections and haematomas, which have a similar incidence, the complication rate was higher in Group 1 patients. Furthermore, the rate occurrence of Frey's syndrome was $20.33 \%$ in Group 1 and $0 \%$ in Group $2[\mathrm{P}<0.05]$. Transient facial nerve weakness was significantly more frequent in Group $1(10.16 \%)$ than in Group $2(3.125 \%)[\mathrm{P}<0.05]$. The presence of fistulas, dip skin and accessory spinal nerve injury was significantly more frequent in Group $1[\mathrm{P}<0.05]$.

\section{Discussion}

In 1903 for first Gutierrez described the parotidectomy approach for benign parotid neoplasm removal. Then Patey ${ }^{17}$, and Patey and Thackeray ${ }^{18}$ described the concept of superficial parotidectomy for benign tumours of the parotid gland. This technique is used when faced with tumours greater than $4 \mathrm{~cm}$ in diameter, located in the deep portion of the gland and in recurrences ${ }^{19}$. Parotidectomy is used in these tumours because excision of the tumour would be incomplete using extracapsular dissection techniques. Foresta et al. ${ }^{20}$, in a recent review and ensuing meta-analysis based on 123 studies over the last 65 years, compared the two techniques and found fewer complications and recurrences in the extracapsular dissection. They concluded that in patients with unilateral pleomorphic adenoma, located in the superficial lobe, sized less than $4 \mathrm{~cm}$ and with no clinical involvement of cranial nerve VII, extracapsular dissection represents a viable alternative option to superficial parotidectomy in terms of successful outcome, convenience and ease of performance. According to Foresta et al., in our study, we perform 123 superificial parotidectomy related to exeresis of disease recurrences, tumours located in the deep portion of the parotid gland or larger than $4 \mathrm{~cm}$. Superficial parotidectomy, however, is not free from complications. We can include, for example, the presence of an unsightly scar especially in women and other functional complications such as Frey's syndrome, facial paralysis, haematoma and fistula. For this reason, the introduction of the face-lift by Appiani and Delfino in $1984{ }^{10}$ produces less skin scarring. This surgical approach alone, however, cannot eliminate the depression of the skin after the removal of a tumour. Actually, the removal of the tumour leaves a cavity which results in a facial asymmetry with unpleasant aesthetic outcome. Furthermore, the lack of interface between the muscle-aponeurotic residual parenchyma and skin predisposes to the onset of salivary fistula and Frey Syndrome. Frey's syndrome or auriculotemporal nerve syndrome was described for the first time by Lucy Frey in $1923^{7}$ and is characterised by the appearance of redness, pain, sweating and heat in the parotid region following gustatory stimulus. This is caused by an abnormal post-parotidectomy reinnervation of the auriculotemporal nerve that eventually causes improper innervation to the sweat glands of the skin. To prevent this type of syndrome, a barrier must be formed between the postganglionic parasympathetic nerve fibres and sweat glands of skin flap, thereby preventing this type of connection ${ }^{891221-28}$. The percentage of this syndrome in the literature varies widely. This could be due to the fact that most of the time there is a late onset of this syndrome compared to the short-term post-operative follow-up reported. Bremerich, for example, analysed the occurrence of Frey's syndrome in 372 patients who had a benign tumour of the parotid gland removed. In this study,

Table I. Results of $\chi^{2}$ test of group 1 vs group 2 .

\begin{tabular}{lccc} 
& Group 1 & p value \\
$\mathrm{n}$ & 59 & 64 & $<0.05$ \\
Frey's syndrome & $12(20.33 \%)$ & $0(0.0 \%)$ & $<0.05$ \\
Transient facial nerve weakness & $6(10.16 \%)$ & $2(3.125 \%)$ & $<0.05$ \\
Fistula & $8(13.55 \%)$ & $2(3.125 \%)$ & $<0.05$ \\
Dip skin & $8(13.55 \%)$ & $2(3.125 \%)$ & $>0.05$ \\
Wound infection & $2(3.38 \%)$ & $1(1.56 \%)$ & $>0.05$ \\
Haematoma & $5(8.47 \%)$ & $3(4.68 \%)$ & $>0.05$ \\
Facial paralysis & $1(1.69 \%)$ & $0(0.00 \%)$ & \\
\hline
\end{tabular}


we can verify that while about $50 \%$ of Frey's syndrome developed within 12 months after surgery, approximately $20 \%$ patients developed it after 24 months ${ }^{29}$. Precisely for this reason, we believe that our study, which has a mean follow up of 84 months, makes a valid contribution to the literature and achieves very good results regarding the occurrence of this syndrome. To remedy functional and aesthetic complications, various possible treatments are described, such as radiotherapy, oral medication and botulinum toxin or surgical techniques. If symptoms are of low intensity, however, they do not require any type of treatment ${ }^{17-22}$. The use of non-biological materials such as acellular dermis may decrease the incidence of Frey's syndrome, but greatly increases the incidence of salivary fistula ${ }^{30}$. Some authors suggest the use of the temporoparietal fascia flap in case of surgical gaps larger than $3 \mathrm{~cm}$, in spite of significant decreases in the rate of Frey's syndrome, and it can cause other types of functional complications such as paralysis of the facial nerve, haematoma and aesthetic complications such as alopecia and extension of the surgical scar in the temporal region. In addition, compared to other surgical flaps, the time of duration greatly increases ${ }^{31-33}$.

The SCM flap is another flap described in the literature that can lower the onset of the Frey's syndrome. It is easy to set up, but has a greater risk of complications such as spinal accessory nerve injury, neck pain and cranial haematoma ${ }^{34-37}$. In addition, Sanabria ${ }^{38}$ in a recent study found that it greatly lowers the onset of Frey's syndrome. Indeed, we are accustomed to using this type of technique only in the case of recurrences that require a second surgery.

Precisely for the type of complications described for other reconstructive techniques, we believe that the SMAS flap is effective for resurfacing the surgical cavity after parotid surgery. It may, in fact, prevent Frey's syndrome, fill the depression and preserve facial symmetry. The withdrawal of the SMAS flap is very simple because the initial surgical incision is followed, the flap from the parotid fascia is separated and prepared to rebuild the cavity ${ }^{39}{ }^{40}$. Certainly the use of the SMAS flap to improve post-parotidectomy defects is not new. The first to use this type of flap was reported by Rappaport and Allison ${ }^{11}$ who studied 112 patients and found only 2 cases of Frey's syndrome. The same flap was used by Casler et al. in $1991{ }^{41}$ who found no cases of of Frey's syndrome and by Bonanno and Casson in $1992{ }^{42}$ with excellent results. Cesteleyn et al., in $2002^{31}$, also showed that with the SMAS flap the timing of the recovery of the facial nerve decreases from 3 to 1.5 months. Honig in $2005^{16}$ and Meningaud in $2006{ }^{43}$ continued to propose this type of post-parotidectomy flap. Curry et al. in two studies ${ }^{44}{ }^{45}$ explained how the SMAS flap together with fat grafting can improve facial asymmetry and prevent Frey's syndrome. Wille-Bischofberger et al. ${ }^{46}$ in their study analysed the effectiveness of SMAS flap reconstruction compared to a group where the flap had not been used. The same flap was used by Zhao et al. ${ }^{47}$ and by Arden et al. ${ }^{48}$ with excellent results. The effectiveness of this type of flap has also been reported by Durgut et al. ${ }^{49}$ and by Barbera et al. ${ }^{50}$ in two very interesting publications. Both explain that the use of the SMAS flap prevents Frey's syndrome and provides very satisfactory aesthetic results. The use of this flap, however, is not recommended in the case of malignant tumours, because the SMAS flap extends into the superficial capsular layers of the parotid gland, and in patients with thin subcutaneous tissue ${ }^{5152}$. The use of reconstruction technique in our study was associated with a substantial decrease in Frey's syndrome in Group 1 patients (20.33\%) compared to Group $2(0.00 \%)$ and in deep skin in Group 1 patients $(13.55 \%)$ compared to Group $2(.125 \%)$.

\section{Conclusions}

In conclusion, the results of this study reveal that there was a statistically significant difference in functional and aesthetic post-parotidectomy complications between Group 1 and Group 2. The onset of Frey's syndrome decreased in the case of reconstruction with SMAS flap. Moreover, thanks to a specific questionnaire on patient satisfaction, in aesthetic terms reconstruction with SMAS flap gave a higher level of satisfaction.

\section{References}

1 Tian Z, Li L, Wang L, Hu Y, et al. Salivary gland neoplasms in oral and maxillofacial regions: a 23-year retrospective study of 6982 cases in an eastern Chinese population. Int J Oral Maxillofac Surg 2010;39:235-42.

2 Scianna JM, Petruzzelli GJ. Contemporary management of tumors of the salivary glands. Curr Oncol Rep 2007;9:134-8.

3 Snow GB. The surgical approaches to the treatment of parotid pleomorphic adenomas, in McGurk M, Renehan A (eds): Controversies in the Management of Salivary Gland Disease. Oxford, Oxford University Press, 200, pp 57-63.

4 O'Brien CJ. Current management of benign parotid tumours - The role of limited superficial parotidectomy. Head Neck 2003;25:946.

5 Beahrs OH, Adson MA. The surgical anatomy and the technic of parotidectomy. Am J Surg 1958;95:885.

6 Nitzan D, Kronenberg J, Horowitz Z, et al. Quality of life following parotidectomy for malignant and benign disease. Plast Reconstr Surg 2004;114:1060-7.

7 Frey L. Le syndrome du nerfauriculo-temporal. Rev Neurol 1923;2:97-104.

8 de Bree R, van der Waal I, Leemans R. Management of Frey Syndrome. Head Neck 2007;29:773-8.

9 Linder TE, Huber A, Schmid S. Frey's syndrome after parotidectomy: a retrospective and prospective analysis. Laryngoscope 1997;107:1496-501. 
10 Appiani E. Plastic incisions for facial and neck tumors. Ann PlastSurg 1984;13:335-52.

11 Allison GR, Rappaport I. Prevention of Frey's syndrome with superficial musculoaponeurotic system interposition. Am J Surg 1993;166:407e410.

12 Yoo YM, Lee JS, Park MC, et al. Dermofat graft after superficial parotidectomy via a modified face-lift incision to prevent Frey Syndrome and depressed deformity. J Craniofac Surg 2011;22:1021-3.

13 Owsley JQ Jr. SMAS-platysma facelift. A bidirectional cervicofacial rhytidectomy. Clin Plast Surg 1983;10:429-40.

14 Califano L, Zupi A, Giardino C. Accuracy in the diagnosis of parotid tumours. J Craniomaxillofac Surg 1992;20:354-9.

15 Sato K, Richardson A, Timm DE. One step iodine starch method for direct visualization of sweating. Am J Med Sci 1988;295:528-31.

16 Honig JF. Omega incision face-lift approach and SMAS rotation advancement flap in parotidectomy for prevention of contour deficiency and conspicuous scars affecting the neck. Int J Oral Maxillofac Surg 2005;34:612-8.

17 Patey DH. The present position of parotidectomy in the surgery of the parotid gland. Arch MiddxHosp 1954;4:91.

18 Patey DH, Thackray AC. The treatment of parotid tumours in the light of a pathological study of parotidectomy material. Br J Surg 1958;45:477.

19 Dell'Aversana Orabona G, Bonavolontà P, et al. Surgical management of benign tumors of the parotid gland: extracapsular dissection versus superficial parotidectomy - our experience in 232 cases. J Oral Maxillofac Surg 2013;71:410-3.

20 Foresta E, Torroni A, Di Nardo F, de Waure C, et al. Pleomorphic adenoma and benign parotid tumors: extracapsular dissection vs superficial parotidectomy - review of literature and meta-analysis. Oral Surg Oral Med Oral Pathol Oral Radiol 2014;117:663-76.

21 Harper KE, Spielvogel RL. Frey's syndrome. Int J Dermatol 1986;25:524-6.

22 Hays LL, Novack AJ, Worsham JC. The Frey Syndrome: a simple, effective treatment. Otolaryngol Head Neck Surg 1982;90:419-25.

23 Schulze-Bonhage A, Schroder M, Ferbert A. Botulinum toxin in the therapy of gustatory sweating. J Neurol 1996;243:143-6.

24 Davis O. Management of Frey's syndrome (Letter). JAMA $1985 ; 254: 3421$.

25 Dulguerov P, Marchal F, Gysin C. Frey Syndrome before Frey: the correct history. Laryngoscope 1999;109:1471-3.

26 Demirci U, Basut O, Noyan B, et al. The efficiacy of sternocleidomastoid muscle flap on Frey's Syndrome via a novel test: galvanic skin response. Indian J Otolaryngol Head Neck Surg, doi: 10.1007/s12070-012-0492-y.

27 Santos RC, Chagas JF, Bezerra TF, et al. Frey syndrome prevalence after partial parotidectomy. Braz J Otorhinolaryngol 2006;72:112-5.

28 Sood S, Quraishi MS, Bradley PJ. Frey's syndrome and parotid surgery. Clin Otolaryngol Allied Sci 1998;23:291-301.

29 Bremerich A, Eufinger H, Rustemeyer J, et al. Frey-syndrome. Mund Kiefer Gesichts Chir 2001;5:33-6.
30 Govindaraj S, Cohen M, Genden EM, et al. The use of acellular dermis in the prevention of Frey's syndrome. Laryngoscope 2001;111:1993-8.

31 Ahmed OA, Kolhe PS. Prevention of Frey's syndrome and volume deficit after parotidectomy using the superficial temporal artery fascial flap. Br J Plast Surg 1999;52;256-60

32 Sultan MR, Wider TM, Hugo NE. Frey's syndrome: prevention with temporoparietal fascial flap interposition. Ann Plast Surg 1995;34:292-7.

33 Cesteleyen L, Helman J, King S, et al. Temporoparietal fascia flaps and superficial muscoloaponeurotic system plication in parotid surgery reduces Frey's syndrome. J Oral Maxillofac Surg 2002;60:1284-97.

34 Kornblut AD, Westphal P, Miehlke A. The effectiveness of a sternomastoid muscle flap in preventing post-parotidectomy occurrence of the Frey syndrome. Acta Otolaryngol 1974;77:368-73.

35 Gooden EA, Gullane PJ, Irish J, et al. Role of the sternocleidomastoid muscle flap preventing Frey's syndrome and maintaining facial contour following superficial parotidectomy. J Otolaryngol 2001;30:98-101.

36 Filho WQ, Dedivitis RA, Rapoport A, et al. Sternocleidomastoid muscle flap preventing Frey syndrome following parotidectomy. World J Surg 2004;28:361-4.

37 Zhi K, Ren W, Gao L, et al. Face-lift incision combined with sternomastoid muscular flap in parotidectomy. Aesthetic Plast Surg 2011;35:558-62.

38 Sanabria A, Kowalski LP, Bradley P, et al. Sternocleidomastoid muscle flap in preventing Frey's syndrome after parotidetomy: a systematic review. Head Neck 2012;34:598.

39 Baj A, Beltramini GA, Demarchi M, et al. Bilateral SMAS rhytidectomy in parotid recurrent pleomorphic adenoma. Acta Otorhinolaryngol Ital 2011;31:256-8.

40 Deganello A, Gitti G, Parrinello G, et al. Cost analysis in oral cavity and oropharyngeal reconstructions with microvascular and pedicled flaps. Acta Otorhinolaryngol Ital 2013;33:380-7.

41 Casler JD, Conley J. Sternocleidomastoid muscle transfer and superficial musculoaponeurotic system plication in the prevention of Frey's syndrome. Laryngoscope 1991;101:95-100.

42 Bonanno P, Casson P. Frey's syndrome: a preventable phenomenon. Plast Reconstr Surg 1992;89:452 and 456.

43 Meningaud JP, Bertolus C, Bertrand JC. Parotidectomy: assessment of a surgical technique including facelift incision and SMAS advancement. J Craniomaxillofac Surg 2006;34:34-7.

${ }_{44}$ Curry JM, Fisher KW, Heffelfinger RN, et al. Superficial musculoaponeurotic system elevation and fat graft reconstruction after superficial parotidectomy. Laryngoscope 2008;118:210-5.

45 Curry JM, King N, Reiter D, et al. Meta-analysis of surgical techniques for preventing parotidectomy sequelae. Arch Facial Plast Surg 2009;11:327-31.

46 Wille-Bischofberger A, Rajan GP, Linder TE, et al. Impact of the SMAS on Frey's syndrome after parotid surgery: a prospective, long-term study. Plast Reconstr Surg 2007;120:1519-23. 
47 Zhao HW, Li LJ, Han B, et al. Preventing post-surgical complications by modification of parotidectomy. Int J Oral Maxillofac Surg 2008;37:345-9.

48 Arden RL, Miguel GS. Aesthetic parotid surgery: evolution of a technique. Laryngoscope 2011;121:2581-5.

49 Durgut O, Basut O, Demir UL, et al. Association between skin flap thickness and Frey's syndrome in parotid surgery. Head Neck 2013;35:1781-6.

50 Barberá R, Castillo F, D’Oleo C, et al. Superficial muscu- loaponeurotic system flap in partial parotidectomy and clinical and subclinical Frey's syndrome. Cosmesis and quality of life. Head Neck 2014;36:130-6.

51 Casani AP, Cerchiai N, Dallan I, et al. Benign tumours affecting the deep lobe of the parotid gland: how to select the optimal surgical approach. Acta Otorhinolaryngol Ital 2015;35:80-7.

52 Chulam TC, Noronha Francisco AL, Goncalves Filho J. Warthin's tumour of the parotid gland: our experience. Acta Otorhinolaryngol Ital 2013;33:393-7.

Received: April 15, 2015 - Accepted: September 3, 2015

Address for correspondence: Giovanni Salzano, Maxillofacial Surgery Unit, Department of Odontostomatological and Maxillofacial Sciences, Federico II University of Naples, via Pansini, 5, 80131 Naples, Italy. E-mail: giovannisalzanomd@gmail.com 